\title{
BMJ Open Do autistic patients change healthcare services utilisation through the transition age? An Italian longitudinal retrospective study
}

\author{
Sara Tunesi (D) , ${ }^{1}$ Marco Bosio, ${ }^{2}$ Antonio Giampiero Russo (D) ${ }^{1}$
}

To cite: Tunesi S, Bosio M, Russo AG. Do autistic patients change healthcare services utilisation through the transition age? An Italian longitudinal retrospective study. BMJ Open 2019;9:e030844. doi:10.1136/ bmjopen-2019-030844

- Prepublication history for this paper is available online. To view these files, please visit the journal online (http://dx.doi. org/10.1136/bmjopen-2019030844).

Received 03 April 2019 Revised 27 September 2019 Accepted 03 October 2019

Check for updates

(C) Author(s) (or their employer(s)) 2019. Re-use permitted under CC BY-NC. No commercial re-use. See rights and permissions. Published by BMJ.

${ }^{1}$ Epidemiology Unit, Agency for Health Protection of Milan, Milan, Italy

${ }^{2}$ Agency for Health Protection of Milan, Milan, Italy

Correspondence to Dr Antonio Giampiero Russo; agrusso@ats-milano.it

\section{ABSTRACT}

Objectives This paper aims to provide an estimate of the prevalence rate of autism spectrum disorder (ASD) in 8-year-olds in 2017 based on administrative databases and to investigate the change in healthcare service use during the healthcare transition age of 18 .

Design This research is based on a longitudinal retrospective cohort study.

Setting The data is drawn from the Italian Administrative Healthcare Database (2010-2017).

Participants We identified 5607 ASD patients; 331

ASD patients from 2012 to 2015 in the calendar year of their 18th birthday were selected and their health service utilisation during a 5-year period-ranging from 2 years preceding and succeeding their 18th year-were investigated.

Interventions None.

Primary and secondary outcome measures Prevalence, incidence and proportion of ASD patients receiving specific healthcare services were included in the outcome measures.

Results Prevalence of ASD at age 8 was 5.4/1000. Global access to health and social services was lower both before and after age 18 (46.5\% at $16 ; 68.0 \%$ at $18 ; 54.1 \%$ at 20$)$. The percentage of patients receiving a neuropsychiatric consultation decreased after age 18 (30.8\% at 18 ; $5.4 \%$ at 20 ). Community mental health services (CMHS) utilisation rate increased above 18 years of age. Regarding psychiatric visits, for both outpatient and CMHS, an increase was observed from $17.8 \%$ at age 18 to $25.4 \%$ at age 20. The utilisation of rehabilitation services decreased with age, dropping from $17.8 \%$ at age 16 to $1.8 \%$ at age 20. Psychiatric outpatient services remained stable across ages at about $14 \%$.

Conclusion Our findings suggest that ASD patients changed clinical reference services with age from neuropsychiatric and rehabilitative services towards psychiatric and community-based services as they transitioned from paediatric to adult healthcare services.

\section{INTRODUCTION}

Autism spectrum disorder (ASD) is a brainbased chronic neurodevelopmental disorder with lifelong impacts. It is characterised and diagnosed by impairments in social communication and social interaction with the
Strengths and limitations of this study

- Longitudinal retrospective cohort study based on Administrative Healthcare Database: real-world diagnostic patterns of a large and unselected population (3.5 million habitants).

- Estimation of prevalence and incidence rates, differences in comorbidity and healthcare services utilisation in an unselected retrospective longitudinal cohort of autism spectrum disorder patients from 16 to 20 years of age.

- Diagnosis codes and healthcare services utilisation based only on the administrative data.

presence of restricted, repetitive behaviours. ${ }^{1}$ Onset of ASD typically occurs by age 3, although some studies suggest that symptoms can emerge between 6 and 18 months of age and may not be fully manifested until school age. ${ }^{23}$ Children, adolescents and adults with ASD can often present a number of comorbidities including psychiatric conditions, intellectual disabilities, developmental delay, epilepsy, anxiety, language and motor difficulties, and depression. ${ }^{4-7}$

The aetiology of ASD remains largely unexplained. It seems to be highly heritable, ${ }^{8}$ and some environmental risk factors ${ }^{9}$ and parental age ${ }^{10}$ may be involved. The prevalence of ASD has increased in the last decades, although the reasons for this increase are not fully understood. It might be related to aetiologic, non-aetiologic and administrative factors (eg, modified diagnostic criteria, improved access to services and increased public and scientific interest $^{61112}$ ).

A review published in $2012^{13}$ estimated the global prevalence of ASD to be about $1 \%$ $(62 / 10000)$; a more recent study has estimated the prevalence to be $1.5 \%$ in developed countries. ${ }^{14-16}$ In $2014,{ }^{15}$ a prevalence rate of 16.8 per 1000 was estimated for children aged 8 . 
Treatments for ASD vary across the world and even within country regions, and it has been reported that parents with a lower educational level are less successful in obtaining specialist interventions that could improve outcomes. ${ }^{6}$ Treatments for ASD include early parentmediated interventions and behavioural and social treatments. Evidence-based pharmacology in ASD is currently limited to the treatment of co-occurring behaviours or diagnoses, not ASD itself. ${ }^{6}$ Risperidone ${ }^{17}$ and aripiprazole $^{18}$ have improved symptoms of irritability or agitation in children and adolescents with ASD. Methylphenidate, ${ }^{19}$ atomoxetine ${ }^{20}$ and guanfacine ${ }^{21}$ have shown a benefit for attention deficit hyperactivity disorder (ADHD) symptoms in ASD. However, the use of such drugs presents some adverse effects, and their use has been indicated for a specific age period.

While autism is generally considered a disorder of childhood, the rise in ASD prevalence in the last decades has produced an increase of individuals with ASD transitioning from paediatric to young adult medical services resulting in autism rapidly becoming a disorder of adulthood as well. ${ }^{22}$ There is evidence that for young people with special healthcare needs, such as autism, transitioning from paediatric to adult healthcare can be problematic. ${ }^{23}$ The transition process may be especially difficult for young people whose special healthcare needs involve mental health, developmental disabilities or intellectual disabilities. ${ }^{24}$ Moreover, the lack of ASD treatment guidelines for adult patients increases the complexity of healthcare delivery and involves a complicated transition from paediatric to adult healthcare ${ }^{25}$ Very often, the transition to adulthood in people with ASD results in poor outcomes across multiple domains including employment, education, healthcare, social engagement and independent living, ${ }^{26}{ }^{27}$ even in the presence of targeted healthcare transition services. ${ }^{28}$ This may represent problems both for parents ${ }^{27}$ and patients. ${ }^{29}$

Often the transition from the paediatric to the adult healthcare system coincides with an exit from the educational system (ie, high school) where adolescents may receive daily support that further affects service usage. However, to our knowledge, only a few studies have described changes in healthcare service usage during the transition to adulthood in people with ASD. ${ }^{24} 2630$ Administrative claims data can be plentiful, comprehensive, cost-efficient and free from some of the biases that accompany other types of data, such as surveys or selfreports. ${ }^{31}$ Analyses of administrative healthcare databases have the potential to include a large number of individuals and have been successfully used in the study of health outcomes associated with a variety of conditions. ${ }^{3132}$ Studies conducted in the USA ${ }^{33}$ and Canada ${ }^{345}$ have indicated that administrative claims data were able to clearly identify children with ASD.

The purpose of this paper is to provide an estimate of the prevalence of ASD at 8 years of age using administrative databases derived from the largest Northern Italian population. Further, this study investigated the change in healthcare services use during the transition from the paediatric to young adult healthcare systems.

\section{METHODS}

\section{Data collection}

A retrospective cohort study was conducted using the Administrative Healthcare Database of the Agency for Health Protection of Milan (AHD-ATS) from 1 January 2010 to 31 December 2017. Only data regarding patients residing in the ATS were considered. In Italy, the National Healthcare System (NHS) is universal and fully covers the population and the ATS provides care to about 3500000 inhabitants.

Data were obtained from AHD-ATS, which included eight different databases: (1) outpatient activity data (6 million (M) records), such as visits and tests performed by residents in the study area in ambulatories and laboratories; (2) hospital discharge records (1 M); (3) co-payment exemption register (1 M); (4) emergency department (ED) visits (2 M); (5) rehabilitation interventions database $(800000)$, such as visits and rehabilitative therapy (ie, speech therapy, physiotherapy and educative and occupational therapy); (6) community mental health services (CMHS) (100 000) such as psychiatry visits, residential facilities, pharmacological interventions and family support in psychiatric setting; (7) pharmaceutical prescription database $(200 \mathrm{M})$ and (8) community and social services (CSS) (1 M) such as family support, day care centres, community and residential facilities, home care, home care economic aid and hospice.

Demographic information was obtained by record linkage using a unique identifier code with patients' master data and deprivation index by using record linkage with the 2001 General Census of Population and Housing.

ASD patients were defined as individuals having a reported diagnosis of ASD (International Classification of Diseases, Ninth Revision (ICD-9) codes 299.00 to 299.99 or their ICD-10 equivalents) in at least one of the databases during the study period. ${ }^{35}$ For each patient, the calendar year of birth was used as an approximate age value at the time of service utilisation.

\section{Statistical analysis}

\section{Estimation of prevalence and incidence rates}

Prevalence rates were estimated for 2017 at age 8 and incidence rates ranging from 2 to 8 years of age, based on administrative databases. The prevalence rate was obtained by dividing the number of children 8 years old diagnosed with ASD in 2017 or previously, by the population size-of the same age-in the study area as of 1 January 2018, based on the Italian National Institute of Statistics.

The annual incidence rates were obtained by dividing the annual number of children aged 2-8 years, newly diagnosed, by the general population and subtracting the number of ASD diagnoses in preceding years. Binomial 
95\% CI were calculated for the prevalence and incidence rates.

\section{Consumptions and outcome models}

We selected ASD patients from 2012 to 2015 in the calendar year of their 18th birthday, and we investigated health services utilisation during a 5-year period: the 4 years bracketing their 18th year and the 18th year (ie, aged from 16 to 20 ). We investigated the percentage of co-occurring conditions related to other psychiatric diseases; as an outcome variable, we investigated access to services (ie, outpatient, rehabilitation interventions, community/social services, ED access, hospital admissions and neuroleptic drug consumption).

Co-occurring conditions were identified using the chronicity database ${ }^{36}$ that covers the 13 main comorbidity conditions (hypertension, diabetes, dyslipidaemia, chronic obstructive pulmonary disease, heart failure, renal failure, neoplasms, cardiovascular diseases, inflammatory bowel disease, chronic liver diseases, chronic neurological diseases, autoimmune diseases, and endocrine and metabolic diseases). The proportion of ASD patients with a co-occurring psychiatric diagnosis was estimated by searching for psychiatric diagnoses (ICD-10 code: F00 to F99 with F84, autistic disorder, excluded and their ICD-9 conversion according to the database encoding) in the AHD-ATS databases; we assumed that the psychiatric conditions persisted over time after the first psychiatric diagnoses were recorded.

As outcomes, we investigated consumption of outpatient services (psychiatric, neurologic and neuropsychiatric visits; tests and psychological services), ED admissions, rehabilitation interventions, CMHS interventions, hospital admissions (psychiatry and neuropsychiatric hospitalisation), residential services and CSS utilisations.

With regard to neuroleptic drug consumption, we investigated the percentages of ASD patients who had at least one prescription for any psychotropic substances according to the anatomical therapeutic chemical (ATC) classification. We selected all substances with ATC code 'N' (nervous system) excluding anaesthetics (N01) and analgesics (N02). In addition, we included antidepressants (N06A), antipsychotics (N05), anxiolytics/tranquillisers (N05B, N05CD, N05CF), ADHD medication (N06BA) and antiepileptics (N03A) as separate groups. Risperidone (N05AX08), aripiprazole (N05AX12) and valproic acid (N03AX09) consumption were also considered.

The binary responses of co-occurring diseases, other psychiatric diagnoses, service consumptions and outcomes at ages 16-20 were modelled by repeated measurements using a generalised estimating equation approach with a dichotomic response variable. The binary responses for individual ASD patients were assumed to be equally correlated; thus, an exchangeable correlation structure was assumed. Ages were modelled first as a categorical variable with age 18 as reference. Regressions for co-occurring diseases and other psychiatric diagnoses were adjusted by a gender and deprivation index; in addition, logistic regressions for service consumption and outcomes were adjusted for co-occurring diseases and other psychiatric diagnoses.

\section{Patient and public involvement}

Neither patients nor the public were involved in the design or conduct of this study.

\section{RESULTS}

During the period between 2010 and 2017, we identified 5607 patients (4109 male and 1498 female) who met the inclusion criteria. Mean age as of 2017 was 22 years (ranging from 1 to 90 ), 19 years for males (1-88 years) and 30 years for females (2-90 years). Based on administrative data, the prevalence of ASD at 8 years old on 31 December 2017 was 5.4/1000 inhabitants (95\% CI 4.6 to 6.2 ); prevalence for males was about three times that of females; 8.1/1000 inhabitants (95\% CI 6.8 to 9.5) for males and 2.6/1000 inhabitants (95\% CI 1.8 to 3.5) for females. The incidence rate for 2-8 years in 2017 was 2.1/1000 inhabitants/year (95\% CI 1.9 to 2.3). Incidence in males was higher than in females: 3.3 (95\% CI 1.9 to 2.3) for males and 0.8/1000 inhabitants/year (95\% CI 0.6 to 0.9 ) for females.

We included all patients (331) who were 18 years old between 2012 and 2015 (table 1), of whom 257 (77.64\%) were males and 74 (22.36\%) were females. Regarding the deprivation index, at 18 years of age, $11.18 \%$ were in the least deprived quintile, while $20.24 \%$ were in the most deprived quintile; no differences were found in the quintile distribution by calendar year $(\mathrm{p}=0.2)$.

Co-occurring conditions (table 2) were present in about $22 \%$ of patients at 16 years of age and remained constant among ages; no differences were found for gender or deprivation index. In contrast, other psychiatric diagnoses increased from $42.6 \%$ at 16 years of age to $66.5 \%$ at age $18(\mathrm{p}<0.001)$; females had a greater risk than males $(p=0.003)$, and no differences were found for the deprivation index.

The most reported psychiatric condition was mental retardation (F70-F79) at over 30\%; schizophrenia, schizotypal and delusional disorders (F20-F29) were over 20\%; anxiety, dissociative, stress-related, somatoform and other non-psychotic mental disorders (F40-F48) were about 20\%. Behavioural and emotional disorders (F90-F98) reached $15.4 \%$.

Schizotypal and delusional disorders increased from $11.2 \%$ at 16 years old to $26.3 \%$ at age $18(\mathrm{p}=0.001)$; at 16 years old about $30 \%$ of individuals with ASD had intellectual disabilities and that percentage increased with age reaching $39 \%$ at 20 years $(p<0.001)$. We found a greater risk for females regarding mood affecting disorders (F30 F39, $\mathrm{p}<0.001)$ and disorders of adult personality and behaviour ( $\mathrm{F} 60-\mathrm{F} 69, \mathrm{p}=0.009$ ).

The percentage of ASD patients with at least one instance of access to health services by age is reported in 


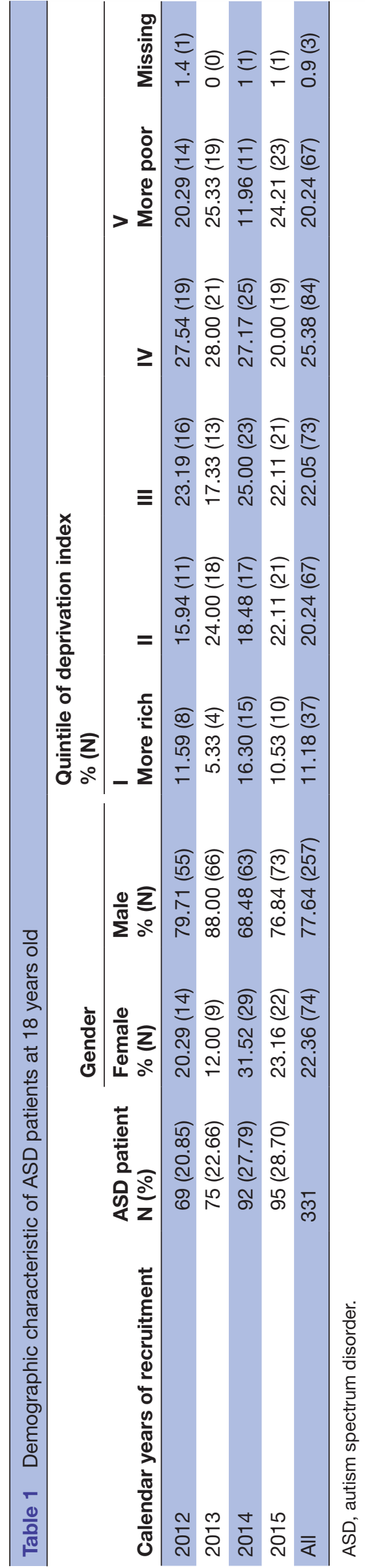

table 3. Global access to health and social services is lower both before and after age 18 years (table 3 ), with comparable levels at 16 and 20 years of age $(p=0.08)$.

The percentage of patients receiving a neuropsychiatric consultation (table 3 ) decreases after 18 years of age (from $30.8 \%$ at age 18 to $5.4 \%$ at age 20 ; $\mathrm{OR}=0.12 ; 95 \% \mathrm{CI}$ 0.07 to 0.32 ). However, neurologist visits increase after 18 years of age (4.8\% at age 18 to $10.6 \%$ at age 20 ; $\mathrm{OR}=2.52$; $95 \%$ CI 1.45 to 4.38 ) and only at 20 years of age reach statistical significance compared with age 18. Psychiatric outpatient visits remained stable across all ages (14\%). Outpatient healthcare services showed a statistically significant decrease after 18 years of age: psychological services (from $15.1 \%$ at age 16 to $3.3 \%$ at age $20 ; \mathrm{OR}_{20 \mathrm{vs} 18}$ $=0.25 ; 95 \%$ CI 0.13 to 0.48 ); rehabilitative services (from $19.9 \%$ to $3.9 \% ; \mathrm{OR}_{20 \mathrm{vs} 18}=0.19 ; 95 \%$ CI 0.11 to 0.34 ) and tests (from $6.6 \%$ to $1.8 \%$; $\mathrm{OR}_{20 \mathrm{vs} 18}=0.20 ; 95 \% \mathrm{CI} 0.08$ to $0.46)$. The ED admission figure showed a non-significant increase from 16 years of age $(19.3 \%)$ to age $18(23.3 \%$, $\mathrm{OR}_{16 \mathrm{vs} 18}=0.91 ; 95 \%$ CI 0.64 to 1.28$)$ and then decreased to $19.0 \%\left(\mathrm{OR}_{20 \mathrm{vs} 18}=0.72 ; 95 \% \mathrm{CI} 0.52\right.$ to 1.01$)$ at age 20 .

As CMHS usually treats adult patients, access to this service was investigated starting from 18 years of age. No access to CMHS was recorded before age 18, and an increase in the utilisation rate was found over age 18 (from $15.1 \%$ at age 18 to $20.8 \%$ at age $20 ; \mathrm{OR}_{20 v s 18}=1.33$; $95 \%$ CI 0.99 to 1.78 ). For psychiatric visits, both in outpatient services and in CMHS, a rate increase was observed after 18 years of age, from $17.8 \%$ at age 18 to $25.4 \%$ at age $20\left(\mathrm{OR}_{20 \mathrm{vs} 18}=1.48 ; 95 \%\right.$ CI 1.08 to 2.02$)$. The utilisation of rehabilitation services decreased with age-from $17.8 \%$ at age 16 to $1.8 \%$ at age $20\left(\mathrm{OR}_{20 \mathrm{vs} 18}=014 ; 95 \%\right.$ CI 0.06 to 0.30 ).

Global hospital admissions decreased with age, with a significant decrease at 18 years of age compared with age 17 (from $22.4 \%$ at age 17 to $16.9 \%$ at age 18 ; $\mathrm{OR}_{17 \mathrm{vs} 18}=$ 1.80 ; $95 \%$ CI 1.25 to 2.59 ). Neuropsychiatric and psychiatric hospital admissions showed opposite trends: neuropsychiatric accesses decreased with age (from $8.8 \%$ at age 16 to $0.3 \%$ at age $20 ; \mathrm{OR}_{20 \text { vi } 18}=0.06 ; 95 \% \mathrm{CI} 0.01$ to 0.38 ) while psychiatric accesses increased (from $1.2 \%$ at age 16 to $6.3 \%$ at age $20 ; \mathrm{OR}_{20 \mathrm{vs} 18}=0.97 ; 95 \% \mathrm{CI} 0.54$ to 1.74 ). It should be noted that neuropsychiatric and psychiatric hospital admissions together remained stable across ages (9.4\% at age 16 to $6.6 \%$ at age $20 ; \mathrm{OR}_{20 v s 18}=0.59 ; 95 \% \mathrm{CI}$ 0.35 to 1.01$)$.

More than $40 \%$ of ASD patients had neurological drug prescriptions, and the percentage increased with age; however, the increase was not statistically significant. Antipsychotics (about 30\%) and antiepileptics (about $20 \%$ ) were the most commonly prescribed drugs, and these percentages did not show a statistically significant increase with age. In detail, risperidone (15\%) and aripiprazole (from $5 \%$ to $11.5 \%$ ) were the antipsychotic drugs most frequently prescribed. Valproic acid was the most frequent epileptic drug prescribed (about 20\% of ASD patients); no statistically significant differences were found across ages. 


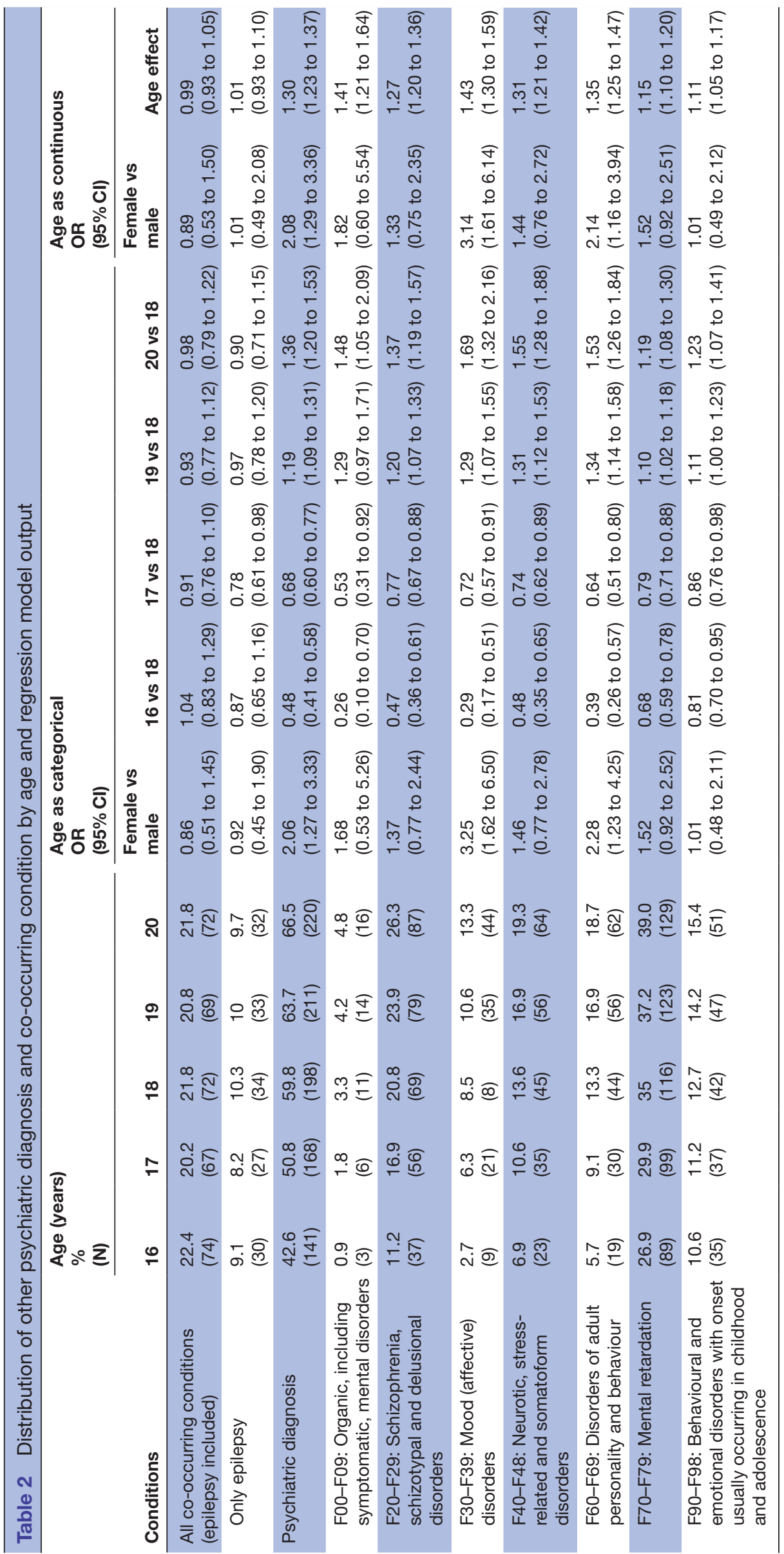




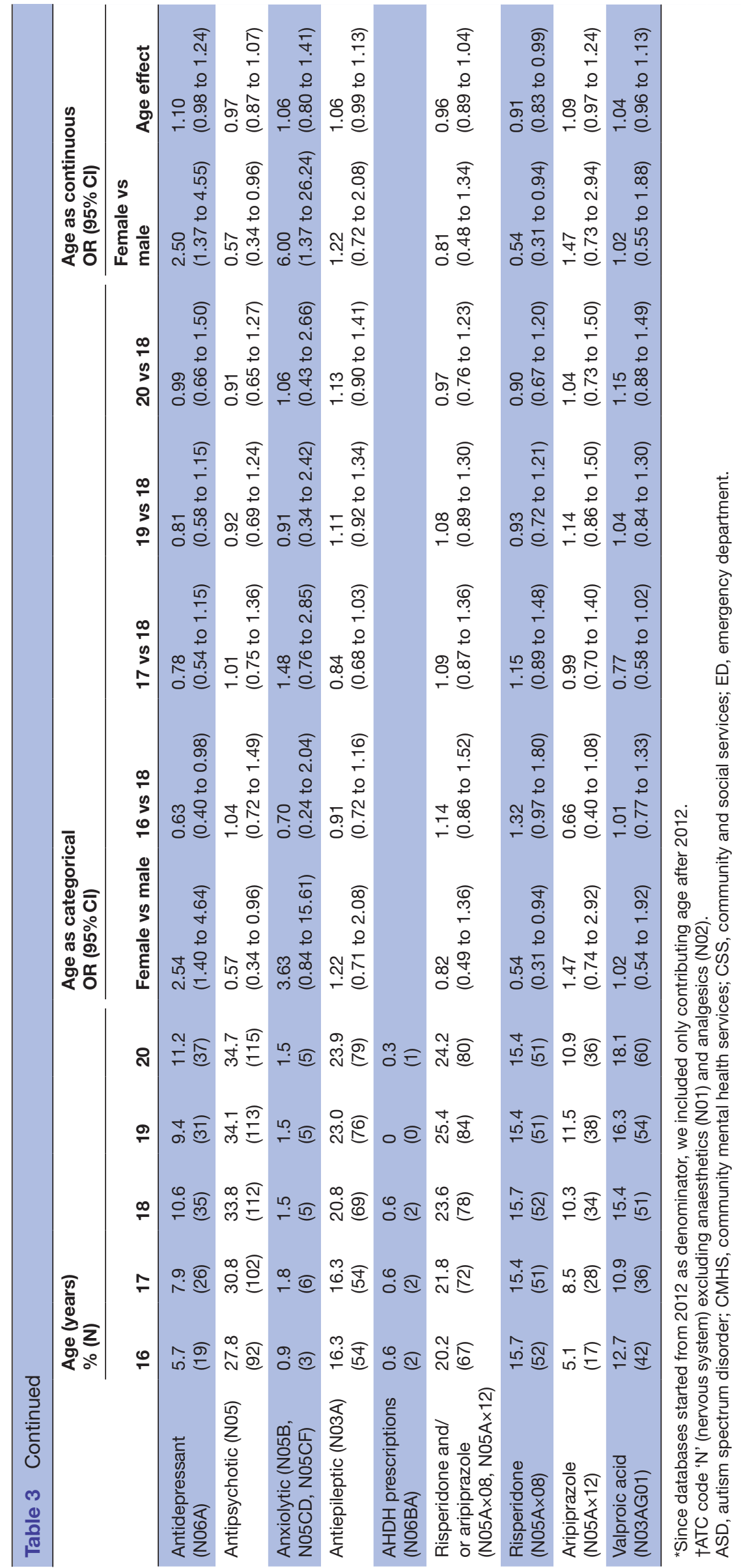




\section{DISCUSSION}

Autism is a major topic in public health debates and between the initial diagnosis and the age of 18 years, the Italian healthcare system provides an efficient management model based on child neuropsychiatry. Child neuropsychiatry is devoted to neurological, behavioural, emotional and psychiatric disorders in childhood and adolescence while psychiatry units usually are devoted only to psychiatric disorders, particularly in adulthood. The results from this study, based on the innovative and integrated use of healthcare and social databases, show that, in the transition to adulthood, there is a change in the models used in taking care of a child diagnosed with autism.

The use of administrative databases allowed us to study real-word diagnostic patterns of a large and unselected population. However, the diagnoses used in this analysis were made by physicians specialised in a variety of disciplines, which may lead to diagnostic imprecision. Indeed, the estimated prevalence of ASD at 8 years of age $(0.54 \%)$ is lower than the autism prevalence of $1.68 \%$ reported by the most recent study. ${ }^{15}$ Nevertheless, our estimate is very close to a value estimated in less recent years. ${ }^{37-39}$ It is also similar to the prevalence reported using administrative databases in Germany during $2012^{40}$ for age groups ranging from 6 to 11 years $(0.6 \%)$ and in France $(0.35 \%)$ from register-based data. ${ }^{41}$ In Italy, few studies reporting autism prevalence have been carried out; in a recent paper, Narzisi et at $t^{42}$ estimated a prevalence of $0.8 \%$ in children aged 7-9. This figure is higher than ours, but the different study setting might have influenced the results, as Narzisi et al based theirs on a sample extracted at the community level. However, if we consider only children included in Narzisi et al with both certified disability and ASD, a prevalence of $0.65 \%$ would be assessed-much closer to our estimate. Since ASD is generally diagnosed after 1 year of age and our data started from 2010, we believe that only a small number of ASD-diagnosed patients who were 8 years old in 2017 were not included. Our underestimation of ASD may be due to a number of reasons: (1) a delayed diagnosis after 8 years old; (2) a lack of recorded diagnosis in administrative databases; (3) a limited tendency to register the autism diagnosis in Lombardy by physicians; (4) a misclassification of the diagnosis or 5) only more serious cases were diagnosed by physicians of the NHS.

With respect to incidence, we estimated for 2017 an annual incidence rate-based on administrative databases-of about 2/1000 for children aged 2-8, but we were able to find only one study for comparison, ${ }^{37}$ which estimated an annual incidence of 1.02/1000 in boys and $0.21 / 1000$ in girls aged 2-8. This figure is lower than ours; however, it referred to 2010 and the incidence of ASD in the subsequent years could have increased. Furthermore, we were able to estimate an incidence for children 2-6 years old between 2015 and 2017, and we estimated (data not shown) 4.30/1000 for 2015, 4.70 for 2016 and 7.30 for 2017. This suggests an increasing trend for ASD diagnoses reported in administrative claims that will be reflected in the prevalence of the following years. However, the increase of ASD is more related to administrative changes, ${ }^{12}$ given that fewer symptoms of autism are now required for diagnosis and that a child with a diagnosis of ASD much more often receives support at school and in the community, ${ }^{43}$ rather than a factor affecting pathogenesis.

Our study investigated the differences in rates of comorbidity and healthcare services utilisation in a retrospective longitudinal cohort of ASD patients from 16 to 20 years old. The ASD cohort used in this study included individuals who had been patients with health/social care services utilisation over 7 years (from 2010 to 2017). Thus, the findings in this cohort could not be connected to general ASD patients during the transition age but to ASD patients who were included in a health/social services pathway and, perhaps, having more serious conditions. Thus, our findings of a high rate (up to $66.5 \%$ ) of psychiatric conditions (including mental retardation) were not completely surprising, even if higher than those reported in other studies $\left(34 \%^{44} ; 54 \%^{5} ; 65 \%^{39}\right)$. In detail, the percentage of anxiety previously reported in a previous study ${ }^{44}$ was similar $(14.4 \%)$ to ours $(19.3 \%)$, as well as depression $(9.9 \%$ vs $13.3 \%)$. The percentage of individuals with epilepsy in our study $(9 \%)$ is comparable with other studies examining the transition age in ASD. ${ }^{44} \mathrm{We}$ observed a high percentage of schizophrenia, schizotypal, and delusional disorders (over 20\%) compared with other studies (between $8 \%$ in adults 545 and $17 \%$ in 22-40 years old ${ }^{7}$ ). This could be related to a change from child neuropsychiatry services to psychiatry services in the young adult phase where personality disorders may be overdiagnosed. Moreover, it must be considered that the diagnosis of other psychiatric conditions was also based on administrative data and thus may depend, at least in part, on which services and specialists were more involved in each patients' care. Surprisingly, we observed an increasing rate of intellectual disability from 16 to 20 years; two possible causes should be considered. On one hand, this trend may be related to the end of the paediatric co-payment exemption at age 18 that previously could overwrite other causes of exemption. On the other hand, the end of compulsory education may cause an increase of intellectual assessment request in order to provide a more specific daily support. In Italy, patients remain in charge of paediatric healthcare services until 18 years of age; however, starting at 16 years of age there may be some overlap in healthcare systems. The results of this study suggest that the type of medical services used for ASD patients changes between 16 and 20 years. Further, comparison between ages showed that general healthcare services utilisation increases from 16 to 18 years old and subsequently decreases.

Neuropsychiatric and rehabilitation services decreased with age as ASD patients began treatment with CMHS and CSS; this suggests a change in the care path for these people. Indeed, the percentage of ASD patients with at 
least one CMHS treatment increased from 18 to 20 years of age. Also, the percentage of ASD patients having psychiatric visits in outpatient care services or CMHS increased from $12.7 \%$ at 16 years old to $25.4 \%$ at 20 years old. This change in patients' reference services was also confirmed by the decreased rate of ASD patients with neuropsychiatric hospitalisation and the corresponding increase of psychiatric hospitalisation, even if globally the hospitalisation in dedicated departments (neuropsychiatric or psychiatric) remained stable across ages. This suggests, together with the higher global access observed at age 18, that ASD patients and their families might look for new clinical reference services around the 18th year and then settle down, even if long-term observation may be necessary. In conclusion, we did not observe a decrease in healthcare services utilisation as recently reported by Nathenson and Zablotsky. ${ }^{30}$ Moreover, psychiatric healthcare services may not be the proper type of support considering the special needs (such as speech therapy, rehabilitation and occupational therapy) of these patients.

The percentage of individuals with ASD who received at least one service related to an ED remains stable with age, although a slight increase in 17-19year olds was observed. This suggests that even if the clinical reference services changed with age a greater need of the ED was not implied.

Even if the current evidence for the effectiveness of antipsychotic drugs in ASD is only moderate, ${ }^{6}$ neuroleptic drugs were frequently used in this cohort of ASD patients and their consumption remained stable across ages; moreover, our findings were similar to frequencies reported in other studies. ${ }^{39} \mathrm{ADHD}$ drugs were less prescribed (less than $0.6 \%$ ) with respect to other reported prescription rates in ASD patients (about 15\%) even considering the patients' age ${ }^{47}$; this may reflect a generally low consumption in Italy of such drugs in childhood. ${ }^{48}$

\section{Strengths and limitations}

The current study used large administrative databases, which made it possible to study real-world diagnostic patterns of a large and unselected population without non-responses, interviews or recall bias issues. However, we must note that we could not include any service utilisation outside the NHS. Furthermore, diagnoses in administrative databases are made by physicians specialised in a variety of disciplines and were not validated, which may lead to diagnostic imprecision. In addition, some diagnoses may not have been reported. With regard to the estimated rate of ASD patients who used healthcare services, we investigated what type of diagnosis these outcomes were associated with and the reasons for such services. However, the CSS and rehabilitation interventions database did not systematically report the type of services provided (ie, speech therapy, rehabilitation, occupational therapy).

The 16-20 age range provides an opportunity to investigate ASD patients during the transition from paediatric to young adult services, and we were able to follow longitudinally a group of ASD patients in transition age without the birth cohort effect. Unfortunately, our cohort was limited to adolescents with ASD who had had at least one healthcare service contact with a diagnosis code related to ASD starting from 2010; thus, ASD patients who did not use healthcare services during this period would not be included. Accordingly, our findings may not be applied to all ASD patients in transition age but represented ASD patients with some healthcare service connection.

Our study suggested a change in the clinical reference services, but we did not find a reduction in the use of healthcare services with age. However, we were not able to include a survey of caregivers in order to investigate any actual difficulties in managing this transition.

\section{CONCLUSION}

Our findings suggest that ASD patients change clinical reference services with age from neuropsychiatric and rehabilitative services towards psychiatric and community-based services. The rise in prevalence, based on administrative data, of ASD in children might lead to a large number of adolescents who will be entering the young adult's healthcare system in the future and will require specific support. More studies are needed to investigate the actual needs of ASD patients in order to plan future public healthcare policies and interventions.

Acknowledgements The authors thank Professor Maria Grazia Valsecchi, Adriano Decarli and Claudio Lucifora for having identified the object of this study as relevant to public health and for having indicated its inclusion in the public announcement that was the subject of an unconditional contribution by Roche. We would like to thank Editage (www.editage.com) for English language editing.

Contributors ST, AGR and MB conceived and devised the study, and ST analysed the data. All authors contributed to the interpretation of the data. ST drafted the article and AGR reviewed and edited the manuscript and approved the version to be published and agree to be accountable for all aspects of the work. The corresponding author attests that all listed authors meet authorship criteria and that no others meeting the criteria have been omitted. ST and AGR accept full responsibility for the work and the conduct of the study, had access to the data and controlled the decision to publish.

Funding The research being reported in this publication was supported by Roche. The funder had no role in study design, data collection and analysis, decision to publish or preparation of the manuscript.

Competing interests None declared.

Patient consent for publication Not required.

Provenance and peer review Not commissioned; externally peer reviewed. Data availability statement № data are available.

Open access This is an open access article distributed in accordance with the Creative Commons Attribution Non Commercial (CC BY-NC 4.0) license, which permits others to distribute, remix, adapt, build upon this work noncommercially, and license their derivative works on different terms, provided the original work is properly cited, appropriate credit is given, any changes made indicated, and the use is non-commercial. See: http://creativecommons.org/ licenses/by-nc/4.0/.

ORCID iDs

Sara Tunesi http://orcid.org/0000-0002-8576-942X

Antonio Giampiero Russo http://orcid.org/0000-0002-5681-5861 


\section{REFERENCES}

1 Associations AP. Diagnostic and Statistical Manual of Mental Disorders (DSM-5). In: 5Th. Washington DC: American Psychiatric Publishing, 2013

2 Lord C, Risi S, DiLavore PS, et al. Autism from 2 to 9 years of age. Arch Gen Psychiatry 2006;63:694-701.

3 Ozonoff S, losif A-M, Baguio F, et al. A prospective study of the emergence of early behavioral signs of autism. J Am Acad Child Adolesc Psychiatry 2010;49:256-66.

4 Bauman ML. Medical comorbidities in autism: challenges to diagnosis and treatment. Neurotherapeutics 2010;7:320-7.

5 Croen LA, Zerbo O, Qian Y, et al. The health status of adults on the autism spectrum. Autism 2015;19:814-23.

6 Lord C, Elsabbagh M, Baird G, et al. Autism spectrum disorder. The Lancet 2018;392:508-20.

7 Vohra R, Madhavan S, Sambamoorthi U. Comorbidity prevalence, healthcare utilization, and expenditures of Medicaid enrolled adults with autism spectrum disorders. Autism 2017;21:995-1009.

8 Colvert E, Tick B, McEwen F, et al. Heritability of autism spectrum disorder in a UK population-based twin sample. JAMA Psychiatry 2015;72:415-23.

9 Volk HE, Lurmann F, Penfold B, et al. Traffic-Related air pollution, particulate matter, and autism. JAMA Psychiatry 2013;70:71-7.

10 Idring S, Magnusson C, Lundberg M, et al. Parental age and the risk of autism spectrum disorders: findings from a Swedish populationbased cohort. Int J Epidemiol 2014;43:107-15.

11 Hansen SN, Schendel DE, Parner ET. Explaining the increase in the prevalence of autism spectrum disorders: the proportion attributable to changes in reporting practices. JAMA Pediatr 2015;169:56-62

12 Lundström S, Reichenberg A, Anckarsäter $\mathrm{H}$, et al. Autism phenotype versus registered diagnosis in Swedish children: prevalence trends over 10 years in general population samples. BMJ 2015;350.

13 Elsabbagh M, Divan G, Koh Y-J, et al. Global prevalence of autism and other pervasive developmental disorders. Autism Res 2012:5:160-79.

14 Lyall K, Croen L, Daniels J, et al. The changing epidemiology of autism spectrum disorders. Annu Rev Public Health 2017;38:81-102.

15 Baio J, Wiggins L, Christensen DL, et al. Prevalence of autism spectrum disorder among children aged 8 years - autism and developmental disabilities monitoring network, 11 sites, United States, 2014. MMWR Surveill. Summ. 2018;67:1-23.

16 Baxter AJ, Brugha TS, Erskine HE, et al. The epidemiology and global burden of autism spectrum disorders. Psychol Med 2015;45:601-13.

17 Kent JM, Kushner S, Ning X, et al. Risperidone dosing in children and adolescents with autistic disorder: a double-blind, placebocontrolled study. J Autism Dev Disord 2013;43:1773-83.

18 Owen R, Sikich L, Marcus RN, et al. Aripiprazole in the treatment of irritability in children and adolescents with autistic disorder. Pediatrics 2009;124:1533-40.

19 Sturman N, Deckx L, van Driel ML. Methylphenidate for children and adolescents with autism spectrum disorder. Cochrane Database Syst Rev 2017;11.

20 Handen BL, Aman MG, Arnold LE, et al. Atomoxetine, parent training, and their combination in children with autism spectrum disorder and attention-deficit/hyperactivity disorder. J Am Acad Child Adolesc Psychiatry 2015;54:905-15.

21 Scahill L, McCracken JT, King BH, et al. Extended-Release guanfacine for hyperactivity in children with autism spectrum disorder. Am J Psychiatry 2015;172:1197-206.

22 Mandell DS. Adults with autism--a new minority. J Gen Intern Med 2013;28:751-2

23 Colver A, Pearse R, Watson RM, et al. How well do services for young people with long term conditions deliver features proposed to improve transition? BMC Health Serv Res 2018;18:337.

24 Kuhlthau KA, Delahaye J, Erickson-Warfield M, et al. Health care transition services for youth with autism spectrum disorders: perspectives of caregivers. Pediatrics 2016;137 Suppl 2:S158-66.

25 Murphy CM, Wilson CE, Robertson DM, et al. Autism spectrum disorder in adults: diagnosis, management, and health services development. Neuropsychiatr Dis Treat 2016;12:1669-86.
26 Roux AM, Shattuck PT, Rast JE, et al. National autism indicators report: transition into young adulthood. Philadelphia, PA: Life Course Outcomes Research Program.

27 Thompson C, Bölte S, Falkmer T, et al. To be understood: transitioning to adult life for people with autism spectrum disorder. PLoS One 2018;13:e0194758.

28 Cheak-Zamora NC, Yang X, Farmer JE, et al. Disparities in transition planning for youth with autism spectrum disorder. Pediatrics 2013;131:447-54.

29 Cheak-Zamora NC, Teti M, First J. 'Transitions are Scary for our kids, and they're Scary for us': family member and youth perspectives on the challenges of transitioning to adulthood with autism. J App/ Res Intellect Disabil 2015;28:548-60.

30 Nathenson RA, Zablotsky B. The transition to the adult health care system among youths with autism spectrum disorder. Psychiatr Serv 2017;68:735-8.

31 Spettell CM, Wall TC, Allison J, et al. Identifying physicianrecognized depression from administrative data: consequences for quality measurement. Health Serv Res 2003;38:1081-102.

32 Abraha I, Serraino D, Montedori A, et al. Sensitivity and specificity of breast cancer ICD-9-CM codes in three Italian administrative healthcare databases: a diagnostic accuracy study. BMJ Open 2018;8:e020627.

33 Burke JP, Jain A, Yang W, et al. Does a claims diagnosis of autism mean a true case? Autism 2014;18:321-30.

34 Diallo FB, Fombonne Éric, Kisely S, et al. Prevalence and correlates of autism spectrum disorders in Quebec: Prévalence et corrélats des troubles Du spectre de l'autisme Au Québec. Can J Psychiatry 2018;63:231-9.

35 Dodds L, Spencer A, Shea S, et al. Validity of autism diagnoses using administrative health data. Chronic Dis Can 2009;29:102-7.

36 Lombaria R. Deliberazione $N^{\circ}$ X / 6164.governo Della Domanda: Avvio Della Presa In Carico Di Pazienti Cronici E Fragili. Determinazioni In Attuazione Dell'art. 9 Della Legge N. 23/. 2015, 2017.

37 Taylor B, Jick H, Maclaughlin D. Prevalence and incidence rates of autism in the UK: time trend from 2004-2010 in children aged 8 years. BMJ Open 2013;3:e003219.

38 Fombonne E. Epidemiology of pervasive developmental disorders. Pediatr Res 2009;65:591-8.

39 Bachmann CJ, Manthey T, Kamp-Becker I, et al. Psychopharmacological treatment in children and adolescents with autism spectrum disorders in Germany. Res Dev Disabil 2013;34:2551-63.

40 Bachmann CJ, Gerste B, Hoffmann F. Diagnoses of autism spectrum disorders in Germany: time trends in administrative prevalence and diagnostic stability. Autism 2018;22:283-90.

41 van Bakel MME, Delobel-Ayoub M, Cans C, et al. Low but increasing prevalence of autism spectrum disorders in a French area from register-based data. J Autism Dev Disord 2015;45:3255-61.

42 Narzisi A, Posada M, Barbieri F, et al. Prevalence of autism spectrum disorder in a large Italian catchment area: a school-based population study within the ASDEU project. Epidemiol Psychiatr Sci 2018;58:1-10.

43 Arvidsson O, Gillberg C, Lichtenstein P, et al. Secular changes in the symptom level of clinically diagnosed autism. J Child Psychol Psychiatr 2018;59:744-51.

44 Davignon MN, Qian Y, Massolo M, et al. Psychiatric and medical conditions in Transition-Aged individuals with ASD. Pediatrics 2018;141:S335-45

45 Stahlberg O, Soderstrom H, Rastam M, et al. Bipolar disorder schizophrenia, and other psychotic disorders in adults with childhood onset AD/HD and/or autism spectrum disorders. J Neural Transm 2004;111:891-902.

46 Lai M-C, Kassee C, Besney R, et al. Prevalence of co-occurring mental health diagnoses in the autism population: a systematic review and meta-analysis. Lancet Psychiatry 2019;6:819-29.

47 Rasmussen L, Bilenberg N, Thomsen Ernst M, et al. Use of psychotropic drugs among children and adolescents with autism spectrum disorders in Denmark: a nationwide drug utilization study. $J$ Clin Med 2018;7.

48 Piovani D, Clavenna A, Cartabia M, et al. Psychotropic medicine prescriptions in Italian youths: a multiregional study. Eur Child Adolesc Psychiatry 2016;25:235-45. 